\title{
Association between frailty and risk of fall among diabetic patients
}

\author{
Xiaojie Wang ${ }^{1, *}$, Zhiyuan Chen ${ }^{2}$, Ziyi Li ${ }^{1}$, Bo Chen ${ }^{3}$, Yong $\mathbf{Q i}^{4,{ }^{*}}$, Guowei $\mathrm{Li}^{1,2}$ and Jonathan D Adachi ${ }^{2,5}$ \\ ${ }^{1}$ Center for Clinical Epidemiology and Methodology (CCEM), Guangdong Second Provincial General Hospital, Guangzhou, China \\ 2Department of Health Research Methods, Evidence, and Impact, McMaster University, Hamilton, Canada \\ ${ }^{3}$ Department of Endocrinology, Guangdong Second Provincial General Hospital, Guangzhou, China \\ ${ }^{4}$ Department of Orthopedics, Guangdong Second Provincial General Hospital, Guangzhou, China \\ ${ }^{5}$ Department of Medicine, McMaster University, Hamilton, Canada
}

Correspondence should be addressed to G Li: lig28@mcmaster.ca

*( $\mathrm{X}$ W and $\mathrm{Y} \mathrm{Q}$ contributed equally to this work)

\begin{abstract}
Background: Several epidemiological studies have demonstrated the risk factors for fall, while few studies investigated the association between frailty and risk of fall in diabetic patients aged $\geq 45$ years.

Methods: In this multicity observational study, participants with type 2 diabetes aged $\geq 45$ years were enrolled. Frailty status was measured by a frailty index $(\mathrm{Fl})$ of deficit accumulation. We used multivariable regression models to examine the relationship between frailty and fall in diabetic patients, and further investigated the associations between frailty and fall in varied subgroups.

Results: A total of 2049 participants with type 2 diabetes were identified in our study. Our results showed a per-S.D. and a per-0.01 increment of FI were associated with an increased risk of fall, with a fully adjusted OR of 1.89 (95\% Cl: 1.50, 2.38), 1.06

( $95 \% \mathrm{Cl}: 1.04,1.09)$, respectively. The effects were magnified when frailty was considered as dichotomous, with an $\mathrm{OR}$ of $3.08(95 \% \mathrm{Cl}: 2.18,4.34)$. In further subgroup analyses, we found that the females, the older, rural residents, individuals with no sitting toilet, people with poor balance performance and those in poor health status were susceptible to fall. Especially, for the risk of fall in the older, a per-s.D. increase of Fl corresponded to an OR of 2.46 (95\% Cl: $1.68,3.62)$. When frailty was regarded as a binary variable, the effect increased to $4.62(95 \% \mathrm{Cl}: 2.54,8.38)$ in the older subgroup.

Conclusion: Frailty was associated with a higher risk of fall in people with type 2 diabetes, and the effects were higher in vulnerable groups. This evidence suggested that more attention should be paid to vulnerable groups for fall prevention.
\end{abstract}
Key Words
- frailty
- fall
- type 2 diabetes
- China
- CHARLS

\section{Introduction}

As a major public health issue, fall is the second leading cause of accidental or unintentional injury-induced deaths worldwide with considerable social and economic burden (1), which could lead to various serious consequences (e.g. fractures, severe soft tissue injuries, hospitalization, and even death) with different severity $(2,3,4)$. The risk of fall increases with aging and those middle-aged and the older are at the highest risk of fall (5). It was estimated that one-third of adults over 65 years old and one-half of adults over 80 fall each year worldwide (6). Approximately 37.3 million falls per year were severe enough to require medical attention, which were responsible for over 17 million disabilityadjusted life years loss (1). However, few studies focused on the prevalence and risk factors of fall among middle-aged and older adults. Therefore, it is urgent to investigate the modifiable risk factors of fall in this population. 
More and more evidence indicating the risk of fall is higher in patients with type 2 diabetes than that in healthy individuals was reported $(7,8)$. However, compared with the general population, higher bone mineral density was found in people with diabetes, which is generally considered as a protective factor for fall-related fractures. The 'diabetes bone paradox' indicates that other risk factors that lead to a higher incidence of fall in diabetic patients do exist. Thus, it is essential to identify the risk factors of fall in diabetic patients. Several common risk factors have been proposed to explain the association between diabetes mellitus and the risk of fall, including the cognitive impairment, poor physical performance, diabetic peripheral neuropathy, poor vision and hearing, and bone joint disorder $(9,10,11,12,13)$. However, frailty, which was found to be one of the most significant risk factors in recent studies (14), has not yet been fully explored in diabetic patients yet.

Frailty is neither total disability nor full health. It refers to a health condition with increased risk for diseases and decreased body functions which is associated with aging $(15,16)$. A multitude of studies manifested that frailty was closely related to adverse outcomes, such as hospitalization, disability, need for care, and death $(17,18$, 19), which were common in diabetic patients. Therefore, it is possible that the frailty status may associate with fall in patients with type 2 diabetes (20). As a result, we performed this study to investigate whether frailty was associated with fall among the middle-aged and older patients with type 2 diabetes.

\section{Methods}

\section{China health and retirement longitudinal study (CHARLS)}

Details of CHARLS are available elsewhere (21). In brief, CHARLS is a national population-based longitudinal health survey conducted by the National School of Development of Peking University, with a target population aged no less than 45 years. Baseline information was colleted in year 2011 and two follow-up surveys were performed every 2 years afterwards (i.e. in year 2013 and 2015, respectively). In order to produce a representative sample, a multi-staged probability sampling strategy was designed, combined with a probability-proportional-tosize sampling technique. Ethical approval for the study was granted by the Ethical Review Committee of Peking University (\#IRB00001052-11015). A total of 17,708 participants from 150 counties or districts that fell within 28 provinces of China were included between June 2011 and March 2012. Finally, 2049 out of 17,708 participants were type 2 diabetic patients.

\section{Data collection}

Face-to-face computer-assisted interviews were adopted at the baseline and every two years during follow-up, which covered a series of questions about socioeconomic status, physical and mental health, individual characteristics and other physical measurements. The venous blood samples of fasting blood were drawn by trained nurses. Whole blood samples were collected for fasting plasma glucose $(4 \mathrm{~mL})$ and glycated hemoglobin $(\mathrm{HbA1c})$ analysis $(2 \mathrm{~mL})$. According to the American Diabetes Association, participants were diagnosed with diabetes if they had either a fasting plasma glucose (FPG) $\geq 7.0 \mathrm{mmol} / \mathrm{L}(126 \mathrm{mg} / \mathrm{dL}), \mathrm{Hb} 1 \mathrm{Ac} \geq 6.5 \%$, or self-reported as having type 2 diabetes (22).

\section{Outcome}

The outcome in this study was fall, which was evaluated based on the following question in the baseline survey: 'Have you fallen down in the last two years?' The answer (and coding) was Yes (' 1 ') or No $\left({ }^{\prime} 0\right.$ ').

\section{The frailty index}

The FI, representing frailty status, was calculated by baseline health deficits of each participant in this study. The construction of the FI is available elsewhere based on the standard procedure and structure conducted by Searle and Rockwood (23). We selected variables that were associated with FI, and scored these variables from 0 to 1 . In this study, the FI questionnaire consists of 39 items about deficit accumulation. It was produced based on the baseline characteristics of participants in CHARLS. These 39 deficit variables included questions about co-morbidities $(n=15)$, disabilities $(n=5)$, and activities of daily living $(n=19)$. Details are shown in Supplementary Table 1 (see section on supplementary materials given at the end of this article).

The answer to each binary variable was dichotomized, where ' 0 ' referred to no deficit, and ' 1 ' referred to the presence of the deficit. For activities of daily living variables, the ratings were classified into four categories: (i) 'have no difficulty' (scored 0); (ii) 'have difficulty but can still do it' (scored 0.33); (iii) 'have difficulty and need help' (scored 0.67); and (iv) 'can't do it' (scored 1). The answer to the

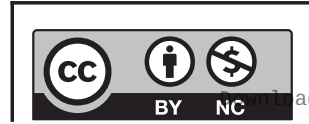

This work is licensed under a Creative Commons Attribution-NonCommercial 4.0 International License. ded from Bioscientifica.com at 04/26/2023 01:31:50AM 
'self-rating of health' was classified into four health states (Excellent $=0$, Very Good $=0.25$, Good $=0.5$, Fair $=0.75$ and Poor $=1$ ). For each individual, the FI was calculated by dividing the total score of all the 39 variables by the scale of the FI questionnaire. For example, if a participant had two deficits which scored 1 point, five deficits which scored 0.33 points each, and all the other deficits scored 0 , the FI would be $(1+1+(0.33 \times 5)) / 39=0.09$.

\section{Other independent variables}

Other independent variables were obtained from faceto-face interviews, including the social demographic information (i.e. age, gender, marital status, residence, and educational attainment), lifestyle (i.e. smoking and drinking status), health-related status (i.e. BMI, balance performance, grip strength, eyesight, co-morbid conditions, and overnight hospitalization in last year), and housing characteristics (i.e. type of toilet).

\section{Statistical analysis}

We used the Pearson chi-square test to examine the connection between categorical variables and the T-test to explore the differences between continuous variables. We calculated the odds ratio (OR), with and without adjustment, for fall by using a series of multivariate logistic regression models based on the FI and other covariates. Three models were constructed: mode 1 including frailty only; model 2 was adjusted for age; and model 3 was additionally adjusted for the other independent variables.

We also conducted sensitivity and subgroup analyses. In order to verify the robustness of the relationship between frailty and fall, the frailty was tested as a dichotomous variable: frailty or robust (depends on whether or not the participant's FI was higher than the mean FI of overall participants (0.24)) in the sensitivity analysis. Subgroup analyses were conducted to investigate the effects of gender (male vs female), age strata (mid-aged: $45 \leq$ age $<65$ vs older participants aged $\geq 65$ ), residence (rural vs urban), balance performance (keep semi-tandem stand above $\geq 10$ s vs keep semi-tandem stand above $<10$ s; keep full-tandem stand above $\geq 30$ s vs keep full-tandem stand above < 30s), type of toilet (with seat vs without seat), and co-morbid conditions (yes vs no).

Statistical analyses were conducted using R software, version 3.5.1 (R Foundation for Statistical Computing, Vienna, Austria). All $P$ values were two-sided. $P$ values less than 0.05 were considered statistically significant.

\section{Results}

There were 2148 participants with type 2 diabetes from 28 provinces in China included in this study (shown in Table 1). The mean participants age was 60.86 (s.D. $=9.58$ ) years. $32.22 \%$ participants were aged over 65 . The mean BMI was 24.47 (s.D. = 3.68) $\mathrm{kg} / \mathrm{m}^{2}$, the mean grip strength was 33.14 (S.D. =40.98) $\mathrm{kg}$, and the mean FI score was 0.12 (s.D. $=0.11$ ). Most participants were married or partnered (87.35\%). About 39\% of them were smokers, and $23 \%$ drank alcohol more than once per month. In terms of balance performance, most participants were able to hold semi-tandem stand for 10 s or more $(97.38 \%)$ and hold full-tandem stand for at least $30 \mathrm{~s}(72.84 \%)$. Approximately $80 \%$ of the individuals had toilets without a seat, $14 \%$ wore glasses or corrective lenses, $83 \%$ had the co-morbid health conditions, and 14\% have overnight hospitalization in the past year.

Table 1 shows the comparisons between the participants with and without fall. Overall, out of 2049 participants who responded, 1648 participants (80.43\%) reported a history of fall in the last 2 years. Mean age and mean FI score of participants with fall were significantly higher than those without fall $(P<0.01$ and $P<0.01$, respectively). There was also a significant difference between gender, residence, balance performance, eyesight, No. of co-morbid conditions, and overnight hospitalization in last year in participants with or without falls $(P<0.05)$.

Table 2 shows that frailty was significantly related to the increased risk of fall in all models. In the basic model (model 1), when frailty was considered as a continuous variable, a per-0.01 and a per-s.D. FI increase were associated with an OR of 1.05 (95\% CI: 1.04, 1.06), and 1.65 (95\% CI: $1.48,1.84$ ), respectively. When frailty was considered as a categorical variable (frailty or robust), it was highly related to an increased risk of fall, with an OR of 3.26 (95\% CI: 2.61, 4.09). In the age-adjusted and fully-adjusted models (model 2 and model 3), the effects decreased slightly but remained significantly positive.

Table 3 illustrates the results of subgroup analyses in multivariable models. We found that the association between frailty and the risk of fall varied among different subgroups including gender, age strata, residence, balance performance, toilet type and health status. For instance, when frailty status was regarded as a continuous variable, per-0.01 and per-S.D. increase in the FI for the older was associated an OR for fall equal to 1.08 (95\% CI: 1.05, 1.12 ) and 2.46 (95\% CI: 1.68, 3.62), respectively. When frailty was used as a dichotomous variable, frailty was associated with larger ORs (4.62, 95\% CI: 2.54, 8.38), 
Table 1 Characteristics of study participants.

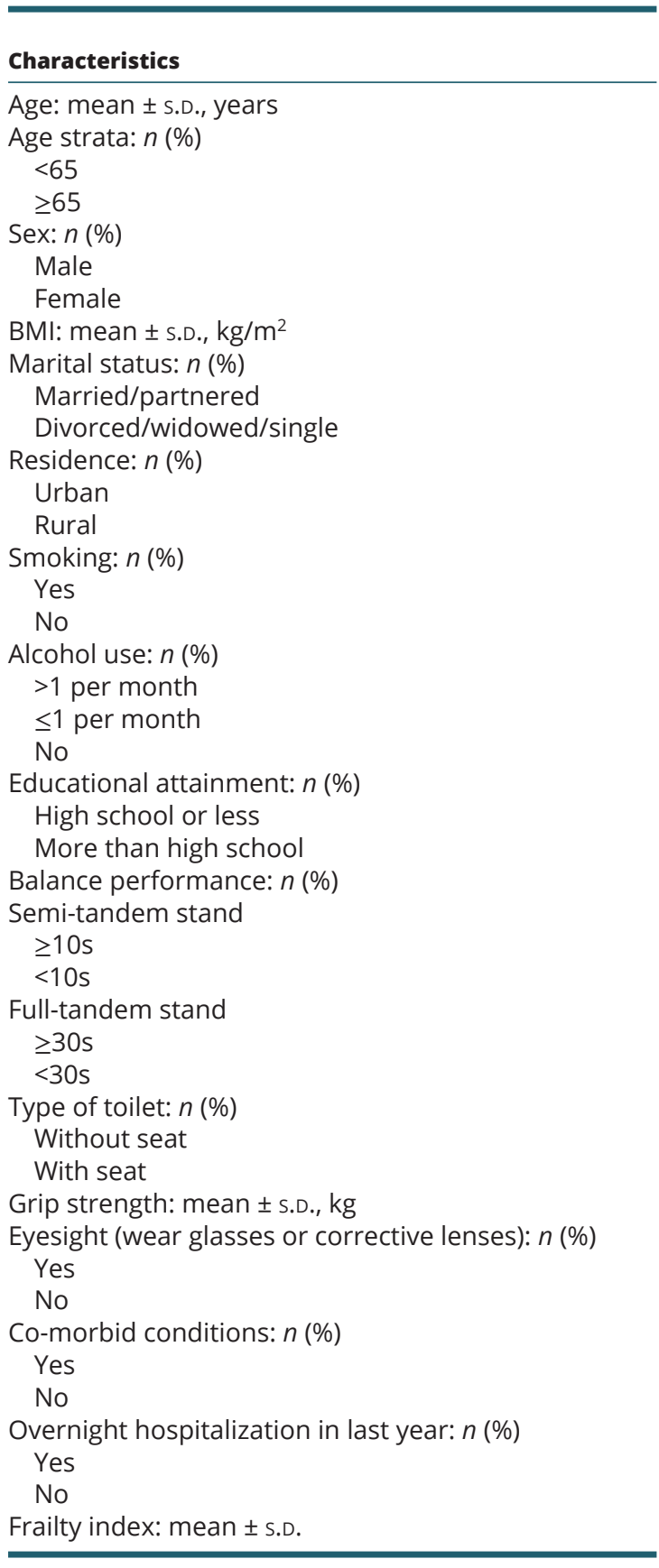

\section{Overall participants \\ $(n=2182)$ \\ $60.86 \pm 9.58$}

1479 (67.78)

$703(32.22)$

$826(46.77)$

$940(53.23)$

$24.47 \pm 3.68$

1905 (87.35)

$276(12.65)$

$646(29.71)$

$1528(70.29)$

847 (39.01)

$1324(60.99)$

$504(23.23)$

$144(6.64)$

$1522(70.14)$

$1896(87.05)$

$282(12.95)$

$1710(97.38)$

$46(2.62)$

$1223(72.84)$

456 (27.16)

1730 (79.87)

$436(20.13)$

$33.14 \pm 40.98$

$294(13.54)$

1878 (86.46)

$1802(82.58)$

$380(17.42)$

296 (13.63)

$1875(86.37)$

$0.12 \pm 0.11$

\section{Participants with/without fall}

$\frac{\text { Yes }(n=401)}{62.22 \pm 9.63} \frac{\text { No }(n=1648)}{60.54 \pm 9.43} \frac{P \text {-value }}{0.001^{\text {a }}}$

$247(61.60) \quad 1142(69.30)$

$154(38.40) \quad 506(30.70)$

$125(38.11) \quad 652(48.15)$

$203(61.89) \quad 702(51.85)$

$24.49 \pm 3.94$

$24.47 \pm 3.61$

$350(87.28) \quad 1443(87.61)$

$51(12.72) \quad 204(12.39)$

$91(22.69) \quad 515(31.40)$

$310(77.31) \quad 1125(68.60)$

$140(35.00) \quad 653(39.65)$

$260(65.00) \quad 994(60.35)$

$83(20.75) \quad 389(23.62)$

$31(7.75) \quad 106(6.44)$

$286(71.50) \quad 1152(69.95)$

$361(90.02) \quad 1423(86.50)$

$40(9.98) \quad 222(13.50)$

$329(95.92)$

$14(4.08)$

1363 (97.78)

$31(2.22)$

$219(66.97) \quad 994(74.46)$

108 (33.03) $\quad 341(25.54)$

$328(82.21) \quad 1307(79.65)$

$71(17.79) \quad 334(20.35)$

$31.49 \pm 53.28$

$33.00 \pm 27.69$

$334(83.29) \quad 1440(87.43)$

$67(16.71) \quad 207(12.57)$

$353(88.03) \quad 1343(81.49)$

$48(11.97) \quad 305(18.51)$

$74(18.50) \quad 202(12.27)$

$326(81.50) \quad 1444(87.73)$

$0.16 \pm 0.11 \quad 0.11 \pm 0.10$ $0.059^{b}$

$0.86^{\mathrm{b}}$

$<0.001^{b}$

$0.087^{b}$

$0.35^{c}$

0.029

$0.001^{b}$

$0.93^{\mathrm{a}}$

(1)

(1)

.

$0.052^{\mathrm{b}}$

$0.006^{\mathrm{b}}$

$0.25^{b}$

$0.46^{a}$

0.029

$0.002^{\mathrm{b}}$

$0.001^{\mathrm{b}}$

$<0.001^{\mathrm{a}}$

aStudent's $t$-test; ${ }^{b}$ Chi-square test.

which was greater than that found in the young (OR equal to $2.49,95 \%$ CI: $1.68,3.68)$.

The same associations were found in other subgroups. The ORs for fall in the female and in the participants with no-sitting toilet were higher than that in the male and in those people with a sitting toilet. The rural residents were more susceptible to fall than the urban residents. Individuals with good balance performance were at less risk of fall compared to those with poor performance. The presence of co-morbid conditions and overnight hospitalization experience in the past year would lead to an increasing risk of fall, while the significant association between frailty and fall in individuals without chronic diseases was not found. The effects of frailty on fall increased when the frailty state was considered as a binary variable, while the effects became non-significant among

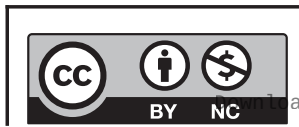

This work is licensed under a Creative Commons Attribution-NonCommercial 4.0 International License. ded from Bioscientifica.com at 04/26/2023 01:31:50AM via free access 
Table 2 Results from univariate and multivariable models regarding relationship between frailty and risk of fall.

\begin{tabular}{l}
\hline \\
\hline Continuous \\
Per-0.01 increase \\
Per-s.D. increase \\
Dichotomized \\
Frailty $^{\mathrm{b}}$ \\
\hline
\end{tabular}

\begin{tabular}{ccc}
\hline \multicolumn{2}{c}{ Model 1 } & \\
\cline { 1 - 1 } \cline { 1 - 1 } OR $(95 \% \mathrm{Cl})$ & & $P$-value \\
$1.05(1.04,1.06)$ & & $<0.001$ \\
$1.65(1.48,1.84)$ & & $<0.001$ \\
& & $<0.001$ \\
$3.26(2.61,4.09)$ & $<$
\end{tabular}

\begin{tabular}{ccc}
\hline \multicolumn{2}{c}{ Model 2} & \\
\cline { 1 - 1 } OR $(95 \% \mathrm{Cl})$ & & $P$-value \\
$1.05(1.04,1.06)$ & & $<0.001$ \\
$1.62(1.45,1.82)$ & $<0.001$ \\
$3.18(2.53,4.00)$ & $<0.001$ \\
\hline
\end{tabular}

\begin{tabular}{ccc}
\hline \multicolumn{2}{c}{ Model 3} & \\
\cline { 1 - 1 } \cline { 1 - 1 } OR $(95 \% \mathrm{Cl})$ & & -value \\
$1.06(1.04,1.09)$ & & $<0.001$ \\
$1.89(1.50,2.38)$ & & $<0.001$ \\
& & $<0.001$ \\
$3.08(2.18,4.34)$ & $<$
\end{tabular}

Model 1 (Basic model): Only frailty included in the model for analysis; Model 2 (age-adjusted model): Model 1 + age; Model 3 (Fully-adjusted model): Model $2+$ gender, BMI, marital status, smoking status, drinking status, residence, education level, balance performance (semi-tandem stand and full-tandem stand), type of toilet, grip strength, eyesight, co-morbid condition, overnight hospitalization in last year.

aTaking robust as reference; ${ }^{b}$ Participants with FI scores higher than mean Fl score of overall participants (0.24) were classified to frailty.

OR, odds ratio.

urban residents, individuals with no-sitting toilet, and participants with no co-morbid health conditions.

\section{Discussion}

In this study, we found a significant association between frailty and risk of fall among individuals with type 2 diabetes. Furthermore, after age and other covariates being adjusted, the association still remained. Our subgroup analyses also provided evidence that the woman, older age, rural living area, poor balance performance, toilet without seat, and poor health condition (i.e. in co-morbid condition and/or hospitalized overnight in the past year) might may strengthen the association between frailty and fall. Our findings contribute to the development of targeted strategies for fall prevention in China.

Table 3 Results of subgroup analyses in multivariable models regarding relationship between frailty and risk of fall.

\begin{tabular}{|c|c|c|c|}
\hline \multirow[b]{3}{*}{ Subgroup } & \multicolumn{3}{|c|}{ Multivariable modela } \\
\hline & \multicolumn{2}{|c|}{ Continuous } & \multirow{2}{*}{$\begin{array}{c}\text { Dichotomized }^{b} \\
\text { OR }(95 \% \mathrm{Cl}), \\
P \text {-value }\end{array}$} \\
\hline & $\begin{array}{c}\text { OR }(95 \% \mathrm{Cl}) \text { for per-0.01 } \\
\text { increase in } \mathrm{Fl}, P \text {-value }\end{array}$ & $\begin{array}{l}\text { OR }(95 \% \mathrm{Cl}) \text { for per-S.D. } \\
\text { increase in } \mathrm{Fl}, P \text {-value }\end{array}$ & \\
\hline \multicolumn{4}{|l|}{ Gender } \\
\hline Male & $1.04(1.01,1.07), 0.006$ & $1.54(1.13,2.08), 0.006$ & $3.50(2.08,5.89),<0.001$ \\
\hline Female & $1.08(1.05,1.11),<0.001$ & $1.99(1.54,2.56),<0.001$ & $2.94(1.95,4.45),<0.001$ \\
\hline \multicolumn{4}{|l|}{ Age strata } \\
\hline$<65$ & $1.04(1.02,1.07),<0.001$ & $1.54(1.20,1.96),<0.001$ & $2.49(1.68,3.68),<0.001$ \\
\hline$\geq 65$ & $1.08(1.05,1.12),<0.001$ & $2.46(1.68,3.62),<0.001$ & $4.62(2.54,8.38),<0.001$ \\
\hline \multicolumn{4}{|l|}{ Residence } \\
\hline Urban & $1.05(1.00,1.09), 0.036$ & $1.68(1.04,2.73), 0.036$ & $1.90(0.90,4.01), 0.092$ \\
\hline Rural & $1.06(1.04,1.09),<0.001$ & $1.92(1.51,2.43),<0.001$ & $3.36(2.36,4.79),<0.001$ \\
\hline \multicolumn{4}{|c|}{ Semi-tandem stand } \\
\hline$\geq 10 \mathrm{~s}$ & $1.06(1.04,1.08),<0.001$ & $1.68(1.42,1.99),<0.001$ & $3.09(2.25,4.24),<0.001$ \\
\hline$<10$ s & $1.09(1.06,1.13),<0.001$ & $1.89(1.53,2.41),<0.001$ & $4.33(1.71,3.17),<0.001$ \\
\hline \multicolumn{4}{|c|}{ Full-tandem stand } \\
\hline$\geq 30 \mathrm{~s}$ & $1.06(1.03,1.09),<0.001$ & $1.57(1.29,1.92),<0.001$ & $3.16(2.15,4.65),<0.001$ \\
\hline$<30 s$ & $1.06(1.03,1.10),<0.001$ & $1.75(1.29,2.37),<0.001$ & $2.72(1.51,4.90),<0.001$ \\
\hline \multicolumn{4}{|l|}{ Type of toilet } \\
\hline Without seat & $1.07(1.04,1.09),<0.001$ & $1.96(1.57,2.46),<0.001$ & $3.46(2.44,4.91),<0.001$ \\
\hline With seat & $1.04(0.98,1.11), 0.19$ & $1.57(0.80,3.10), 0.19$ & $1.92(0.82,4.51), 0.13$ \\
\hline \multicolumn{4}{|c|}{ Co-morbid conditions } \\
\hline No & $1.08(0.97,1.21), 0.16$ & $1.25(0.89,1.77), 0.16$ & $4.12(0.46,36.78), 0.21$ \\
\hline Yes & $1.06(1.04,1.08),<0.001$ & $1.82(1.47,2.25),<0.001$ & $2.98(2.16,4.12),<0.001$ \\
\hline \multicolumn{4}{|c|}{ Overnight hospitalization in last year } \\
\hline No & $1.06(1.04,1.08),<0.001$ & $1.79(1.44,2.24),<0.001$ & $3.01(2.13,4.25),<0.001$ \\
\hline Yes & $1.06(1.00,1.12), 0.047$ & $1.92(1.01,3.67), 0.047$ & $3.21(1.30,7.95), 0.012$ \\
\hline
\end{tabular}

aModel adjusted for age, gender, BMI, marital status, smoking status, drinking status, residence, education level, balance performance (semi-tandem stand and full-tandem stand), type of toilet, grip strength, eyesight, co-morbid condition, overnight hospitalization in last year; ${ }^{\mathrm{b}}$ Taking robust as reference.

OR, odds ratio.

https://ec.bioscientifica.com

https://doi.org/10.1530/EC-20-0405 (c) 2020 The authors Published by Bioscientifica Ltd

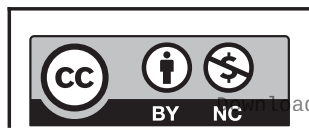

This work is licensed under a Creative Commons Attribution-NonCommercial 4.0 International License. ded from Bioscientifica.com at 04/26/2023 01:31:50AM via free access 
In general, the observed association between the frailty and the risk of fall was enormous in diabetes. The estimated risk of fall in our present study (per-0.01 increment in continuous variable FI corresponded to an OR of 1.06; categorical variables with an OR of 3.08) was consistent with or higher than those reported from several former studies. For example, a cohort study in Canada reported an OR of 1.02 (95\% CI: 1.02, 1.03) in fall for each 0.01 increase in the FI among menopausal women (14). Moreover, a recent meta-analysis informed that frailty was significantly associated with a higher risk of future falls (OR=1.84, 95\% CI: 1.43, 2.38) among community-dwelling older people (24). As frailty status deteriorates with aging, the effects of frailty on fall may be underestimated because the participants of our study included middle-aged adults. Thus, it is highly possible that controlling frailty may play an important role in preventing fall in middle-aged and older people with diabetes.

We found that the association between frailty and risk of fall was different in diabetics with different age, gender and residence (urban or rural area). Frail women, senior citizens, and rural inhabitants were more vulnerable to fall. Our results were consistent with those in previous studies $(25,26)$. Several possible reasons could explain it. First, in the same age group, women have a higher level of FI than men, which suggests that women are more frail than men (27). Second, FI score increases with aging $(28,29)$. Third, rural inhabitants usually have poorer economic conditions and lower education level compared with urban residents, which may contribute to the frailty (30).

In addition, the association between frailty and the risk of fall varied in subgroups by balance performance (semi-tandem stand and full-tandem stand), type of toilet and health states (co-morbid conditions and hospitalizations). Our results illustrated that people with poor balance performance are at a higher risk of fall, compared with people with excellent balance performance. Consistent findings have been reported previously $(31,32)$.

We did not find significant associations between frailty and fall among people with sitting toilet and individuals without a co-morbid condition. The underlying reasons could be that the residents with a sitting toilet generally had good economic status, and thus they would be better able to respond to frailty, which leads to a decreased vulnerability. In addition, no association was seen in frailty leading to fall in individuals with no morbid condition.
There have been a number of mechanisms proposed to explain the association between frailty and fall in diabetes. People with diabetes developed visual impairment, cognitive impairment, musculoskeletal lesion of the lower limbs and vestibular dysfunction. These symptoms could be aggravated by frailty $(33,34)$. Frailty is usually accompanied by low bone mineral density, decreased muscle mass, and chronic inflammation, all of which are typical risk factors for fall (35).

Based on this large population-based study, our results can be used as a reference to prevent diabetic patients to fall in China. Additionally, our findings suggest the potential benefits among people at risk for fall, especially for people with frailty. Fall prevention should be a part of daily routines for people in the state of frailty. Improved quality of life and reduced physical symptoms could contribute to preventing fall. Nonetheless, many research gaps still exist in this area and more studies are needed to further clarify the mechanism of frailty on fall in diabetic patients.

Last but not least, there were some limitations in our study. First, an exact relationship between frailty and fall could not be confirmed because this study was a crosssectional study. Further research is needed to verify it. Second, the same as with previous large-populationbased studies, the data for falls were based on self-reports from participants. Therefore, estimates regarding these conditions may be affected by potential bias. Finally, since our analyses were based on secondary data, further analyses adjusting for some important factors were precluded. For instance, important variables including living environment (36), diabetic status, nutrients intake, musculoskeletal function, and sarcopenia or some other laboratory parameters were not available in this study. It was unknown about whether these variables would represent a threat to validity of our results due to no analyses performed.

\section{Conclusion}

To summarize, our findings suggested that frailty might play an essential role in risk of falls in type 2 diabetes, with higher effects found in vulnerable subgroups. Findings from this study may be helpful for decision-making for fall prevention.

\section{Supplementary materials}

This is linked to the online version of the paper at https://doi.org/10.1530/ EC-20-0405.
This work is licensed under a Creative Commons Attribution-NonCommercial 4.0 International License. ded from Bioscientifica.com at 04/26/2023 01:31:50AM via free access 


\section{Declaration of interest}

The authors declare that there is no conflict of interest that could be perceived as prejudicing the impartiality of the research reported.

\section{Funding}

This study was supported by research grants from the Science Foundation of Guangdong Second Provincial General Hospital (YY2018-002).

\section{Ethics approval and consent to participate}

Each participant included in this study signed a written informed consent form before taking the survey. Ethics approval for the data collection in CHARLS was obtained from the Biomedical Ethics Review Committee of Peking University (IRB00001052-11015). Ethics approval for the use of CHARLS data was obtained from the University of Newcastle Human Research Ethics Committee (H-2015-0290).

\section{Data availability}

The original datasets and questionnaires supporting the conclusions of this article are available at the CHARLS website (http://forum.charls.pku.edu.cn).

\section{Author contribution statement}

$X W, Y Q$, and G L contributed the study concept and design; XW contributed the statistical analysis; X W, Z L and X C drafted the manuscript; Z C, B C, $Y$ Q, G L and J A critically revised the manuscript. X W and $Y Q$ contributed equally to this work.

\section{References}

1 WHO. WHO Global Report on Falls Prevention in Older Age, pp. 1-7. Geneva, Switzerland: World Health Organization, 2007. (available at: (https://www.who.int/ageing/projects/falls_prevention_older_age/en/)

2 Dunn JE, Rudberg MA, Furner SE \& Cassel CK. Mortality, disability, and falls in older persons: the role of underlying disease and disability. American Journal of Public Health 199282 395-400. (https://doi.org/10.2105/ajph.82.3.395)

3 Growdon ME, Shorr RI \& Inouye SK. The tension between promoting mobility and preventing falls in the hospital. JAMA Internal Medicine 2017177 759-760. (https://doi.org/10.1001/ jamainternmed.2017.0840)

4 Inouye SK, Brown CJ \& Tinetti ME. Medicare nonpayment, hospital falls, and unintended consequences. New England Journal of Medicine 2009360 2390-2393. (https://doi.org/10.1056/NEJMp0900963)

5 Volpato S, Leveille SG, Blaum C, Fried LP \& Guralnik JM. Risk factors for falls in older disabled women with diabetes: the women's health and aging study. Journals of Gerontology: Series A, Biological Sciences and Medical Sciences 200560 1539-1545. (https://doi.org/10.1093/ gerona/60.12.1539)

6 Phelan EA \& Ritchey K. Fall prevention in community-dwelling older adults. Annals of Internal Medicine 2018169 ITC81-ITC96. (https:// doi.org/10.7326/AITC201812040)

7 Yang Y, Hu X, Zhang Q \& Zou R. Diabetes mellitus and risk of falls in older adults: a systematic review and meta-analysis. Age and Ageing 201645 761-767. (https://doi.org/10.1093/ageing/afw140)

8 Yau RK, Strotmeyer ES, Resnick HE, Sellmeyer DE, Feingold KR, Cauley JA, Vittinghoff E, De Rekeneire N, Harris TB, Nevitt MC, et al. Diabetes and risk of hospitalized fall injury among older adults. Diabetes Care 201336 3985-3991. (https://doi.org/10.2337/ dc13-0429)
9 Courties A \& Sellam J. Osteoarthritis and type 2 diabetes mellitus: what are the links? Diabetes Research and Clinical Practice 2016122 198-206. (https://doi.org/10.1016/j.diabres.2016.10.021)

10 Markoulli M, Flanagan J, Tummanapalli SS, Wu J \& Willcox M. The impact of diabetes on corneal nerve morphology and ocular surface integrity. Ocular Surface 201816 45-57. (https://doi.org/10.1016/j. jtos.2017.10.006)

11 Park SW, Goodpaster BH, Strotmeyer ES, Kuller LH, Broudeau R, Kammerer C, de Rekeneire N, Harris TB, Schwartz AV, Tylavsky FA, et al. Accelerated loss of skeletal muscle strength in older adults with type 2 diabetes: the health, aging, and body composition study. Diabetes Care 200730 1507-1512. (https://doi.org/10.2337/dc06-2537)

12 Kodl CT \& Seaquist ER. Cognitive dysfunction and diabetes mellitus. Endocrine Reviews 200829 494-511. (https://doi.org/10.1210/er.20070034)

13 Kim MB, Zhang Y, Chang Y, Ryu S, Choi Y, Kwon MJ, Moon IJ, Deal JA, Lin FR, Guallar E, et al. Diabetes mellitus and the incidence of hearing loss: a cohort study. International Journal of Epidemiology 201746 717-726. (https://doi.org/10.1093/ije/dyw243)

14 Li G, Ioannidis G, Pickard L, Kennedy C, Papaioannou A, Thabane L $\&$ Adachi JD. Frailty index of deficit accumulation and falls: data from the Global Longitudinal Study of Osteoporosis in Women (GLOW) Hamilton cohort. BMC Musculoskeletal Disorders 201415 185. (https://doi.org/10.1186/1471-2474-15-185)

15 Gobbens RJ, Luijkx KG \& van Assen MA. Explaining quality of life of older people in the Netherlands using a multidimensional assessment of frailty. Quality of Life Research 201322 2051-2061. (https://doi.org/10.1007/s11136-012-0341-1)

16 Morley JE, Vellas B, van Kan GA, Anker SD, Bauer JM, Bernabei R, Cesari M, Chumlea WC, Doehner W, Evans J, et al. Frailty consensus: a call to action. Journal of the American Medical Directors Association 201314 392-397. (https://doi.org/10.1016/j. jamda.2013.03.022)

17 Boyd CM, Xue QL, Simpson CF, Guralnik JM \& Fried LP. Frailty, hospitalization, and progression of disability in a cohort of disabled older women. American Journal of Medicine 2005118 1225-1231. (https://doi.org/10.1016/j.amjmed.2005.01.062)

18 Almeida OP, Hankey GJ, Yeap BB, Golledge J, Norman PE \& Flicker L. Depression, frailty, and all-cause mortality: a cohort study of men older than 75 years. Journal of the American Medical Directors Association 201516 296-300. (https://doi.org/10.1016/j. jamda.2014.10.023)

19 Theou O, Sluggett JK, Bell JS, Lalic S, Cooper T, Robson L, Morley JE, Rockwood K \& Visvanathan R. Frailty, hospitalization, and mortality in residential aged care. Journals of Gerontology: Series A, Biological Sciences and Medical Sciences 201873 1090-1096. (https://doi. org/10.1093/gerona/glx185)

20 Chao CT, Wang J, Chien KL \& COhort of GEriatric Nephrology in NTUH (COGENT) study group. Both pre-frailty and frailty increase healthcare utilization and adverse health outcomes in patients with type 2 diabetes mellitus. Cardiovascular Diabetology 201817130. (https://doi.org/10.1186/s12933-018-0772-2)

21 Zhao Y, Hu Y, Smith JP, Strauss J \& Yang G. Cohort profile: the China Health and Retirement Longitudinal Study (CHARLS). International Journal of Epidemiology 201443 61-68. (https://doi.org/10.1093/ije/ dys203)

22 American Diabetes Association. 2. Classification and diagnosis of diabetes. Diabetes Care 201740 S11-S24. (https://doi.org/10.2337/ dc17-S005)

23 Searle SD, Mitnitski A, Gahbauer EA, Gill TM \& Rockwood K. A standard procedure for creating a frailty index. BMC Geriatrics $2008 \mathbf{8}$ 24. (https://doi.org/10.1186/1471-2318-8-24)

24 Kojima G. Frailty as a predictor of future falls Among communitydwelling older people: a systematic review and meta-analysis. Journal of the American Medical Directors Association 201516 1027-1033. (https://doi.org/10.1016/j.jamda.2015.06.018)

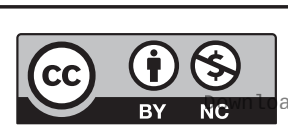

This work is licensed under a Creative Commons Attribution-NonCommercial 4.0 International License. ded from Bioscientifica.com at 04/26/2023 01:31:50AM 
25 Liu Y, Liu G, Wu H, Jian W, Wild SH \& Gasevic D. Sex differences in non-communicable disease prevalence in China: a cross-sectional analysis of the China Health and Retirement Longitudinal Study in 2011. BMJ Open 20177 e017450. (https://doi.org/10.1136/ bmjopen-2017-017450)

$26 \mathrm{Wu} \mathrm{H} \&$ Ouyang P. Fall prevalence, time trend and its related risk factors among elderly people in China. Archives of Gerontology and Geriatrics 201773 294-299. (https://doi.org/10.1016/j. archger.2017.08.009)

27 Shi J, Song X, Yu P, Tang Z, Mitnitski A, Fang X \& Rockwood K. Analysis of frailty and survival from late middle age in the Beijing Longitudinal Study of Aging. BMC Geriatrics 201111 17. (https://doi. org/10.1186/1471-2318-11-17)

28 Mitnitski AB, Rutenberg AD, Farrell S \& Rockwood K. Aging, frailty and complex networks. Biogerontology 201718 433-446. (https://doi. org/10.1007/s10522-017-9684-x)

29 Rockwood K, Mogilner A \& Mitnitski A. Changes with age in the distribution of a frailty index. Mechanisms of Ageing and Development 2004125 517-519. (https://doi.org/10.1016/j.mad.2004.05.003)

30 Wu C, Smit E, Xue QL \& Odden MC. Prevalence and correlates of frailty among community-dwelling Chinese older adults: the China health and retirement longitudinal study. Journals of Gerontology: Series A, Biological Sciences and Medical Sciences 201773 102-108. (https://doi.org/10.1093/gerona/glx098)

31 Belgen B, Beninato M, Sullivan PE \& Narielwalla K. The association of balance capacity and falls self-efficacy with history of falling in community-dwelling people with chronic stroke. Archives of Physical Medicine and Rehabilitation 200687 554-561. (https://doi. org/10.1016/j.apmr.2005.12.027)

32 Brenton-Rule A, Dalbeth N, Bassett S, Menz HB \& Rome K. The incidence and risk factors for falls in adults with rheumatoid arthritis: a systematic review. Seminars in Arthritis and Rheumatism 201544 389-398. (https://doi.org/10.1016/j.semarthrit.2014.08.001)

33 Hewston P \& Deshpande N. Falls and balance impairments in older adults with Type 2 diabetes: thinking beyond diabetic peripheral neuropathy. Canadian Journal of Diabetes 201640 6-9. (https://doi. org/10.1016/j.jcjd.2015.08.005)

34 Boyle PA, Buchman AS, Wilson RS, Leurgans SE \& Bennett DA. Physical frailty is associated with incident mild cognitive impairment in community-based older persons. Journal of the American Geriatrics Society 201058 248-255. (https://doi.org/10.1111/j.15325415.2009.02671.x)

35 Chen LY, Wu YH, Liu LK, Lee WJ, Hwang AC, Peng LN, Lin MH \& Chen LK. Association among serum insulin-like growth factor-1, frailty, muscle mass, bone mineral density, and physical performance among community-dwelling middle-aged and older adults in Taiwan. Rejuvenation Research 201821 270-277. (https://doi.org/10.1089/ rej.2016.1882)

36 Hu J, Xia Q, Jiang Y, Zhou P \& Li Y. Risk factors of indoor fall injuries in community-dwelling older women: a prospective cohort study. Archives of Gerontology and Geriatrics 201560 259-264. (https://doi. org/10.1016/j.archger.2014.12.006)

Received in final form 14 September 2020

Accepted 7 October 2020

Accepted Manuscript published online 8 October 2020 (c) 2020 The authors Published by Bioscientifica Ltd
This work is licensed under a Creative Commons Attribution-NonCommercial 4.0 International License. ded from Bioscientifica.com at 04/26/2023 01:31:50Am 